[CONTRIBUTION FROM THE BUREAU OF STANDARDS, U. S. DEPAR'TMENT OF COMMERCE. I

\title{
GLASS TO METAL JOINTS.
}

\author{
By E. C. MCKFivY AND C. S. 'TAYLOR. ${ }^{1}$ \\ Received April 22, 1920.
}

Contents.-I. Introduction. 2. Earlier Work. 3. Construction of the Joints: (a) soldered joints; (b) fused joints. 4. Auxiliary Metal Parts. 5. Tests of Joints. 6. Applications. 7. Summary.

\section{Introduction.}

In the handling of volatile liquids and liquefied gases and in the manipulation of gases in general in the laboratory, it has been found very useful to have a method for connecting glass and metal tubing by means of a joint which combines the qualities of mechanical strength, resistance to internal pressure, tightness and stability over a considerable range of temperature and which also is suitable for use with a variety of gases. Several methods possessing the above qualities in various degrees have been in use in the laboratories of the Bureat for a number of years. The principles involved in these methods are not new, but in view of the possible wide applicability of joints of this type in laboratory work and their very limited use up to this date, it is desirable to bring together in one place the necessary information for making full use of them. In conjunction with proper auxiliary devices such as metal unions and valves, either of the needle or diaphragm type, a method is provided for joining metal to glass or glass to glass in such a way that in connecting and disconnecting, if proper care is used the weight of each part remains tunaltered.

The purpose of this paper is, first, to give a detailed account of the best methods for the construction of these joints so that they can be reproduced by others; second, to give the results of certain tests upon them; and finally, to outline some of the applications of the joints in Jaboratory work.

\section{Earlier Work.}

The 2 types of joints considered in this work which possess the qualities mentioned above are the platinized glass-tin-metal joint, and the direct glass to metal joint.

Röntgen ${ }^{2}$ soldered into a sheet of metal, a piece of glass, several sq. cm. in area which had been platinized by Dode's method. The plate was then dipped into boiling water without injury to it. Solder was observed to cling very tenaciously to the platinized surface, but by too long contact with the melted solder the platinum was dissolved from the surface of the glass. These observations have been corroborated by us.

Kundt is referred to by Kohlrausch ${ }^{3}$ as the discoverer of the process of

1 Published by permission of the Director of the Bureats of Standards.

${ }^{2}$ Röntgen, Pogg. Ann., I50, 331-3 (1873); Dingl. Poly. J., 2Ir, 136 (1873).

"Kohlrausch, "Iehrbuch d. prakt. Physik," I2te Auflage, rgr4, p. 37. 
soldering metal to platinized glass, which had been covered electrolytically with copper. The original publication on which this reference is based has not been found. As one of the foremost experimentalists of his time, Kundt may very well have discovered this process though no trace of it is found in his publications available to us. The procedure used in platinizing glass is the subject of many publications in the period from 1859 to I87o. The older work has to do with platinizing by means of a colloidal solution of platinum in lavender oil, while later publications are confined largely to platinizing by means of the cathode discharge, which is preferable for mirrors.

Cailletet ${ }^{1}$ described a joint between glass and metal tubing made by covering platinized glass with a coating of copper electrolytically and soldering it into the metal tube as if it were metal. Adequate directions are given for making this joint, and he reported that on his apparatus for the liquefaction of gases a joint of this character, the size not being given, held 300 atmospheres internal pressure. Very little use of this valuable joint has been made since that time, particularly for high pressure work with gases. The Cailletet joint has been used at this Bureau for many years, especially for joining metal thermostat parts to the glass U-tube in which the mercury is actuated, and for sealing metal resistance thermometer bulbs to glass.

Very recently Koenig ${ }^{2}$ has used a joint somewhat similar to the Cailletet joint, to join a glass manometer to a steel osmotic pressure cell. The glass tube was roughened by rubbing with glycerol and emery dust. It was then platinized by painting on a mixture of about two parts of ether to one of alcohol containing $3 \%$ of platinic chloride and $2 \%$ of stearic acid. After drying, the coated glass was heated gently in a Bunsen flame until a platinum coating was obtained. The platinum was first plated electrolytically with gold and then with nickel. A strip of zinc foil was wound around the nickel and soldered into place. This tube was then soldered to the steel cell.

The glass-platinum joint in the form in which a platinum wire is sealed into glass is one of the most familiar of laboratory devices. Joints in which a glass tube is fused to a platinum tube have been in use for a number of years in resistance thermometers of the calorimetric type. ${ }^{3}$ Travers ${ }^{4}$ attributes this type of joint to Callendar, and describes its construction. Karret $^{5}$ has also recently described this type of joint.

A direct glass-to-metal joint was devised by C. A. Kraus. ${ }^{6}$ Its prepara-

1 Cailletet, Séances Soc. franc. phys, 189o, p. 242-3; Séance, Dec. 19, 1890.

${ }^{2}$ Koenig, J. Phys. Chem., 22, 46I (I918).

${ }^{3}$ Dickinson and Mueller, Bur. Standards Bull. 9, 486 (r9r3); (Sci. Paper. 200).

"Travers, "Experimental Study of Gases," p. 22. Macmillan and Co., roor.

"Karrer, This Journal, 40, 928 (I918).

6. U. S. pat. $1,046,084$, Dec. 3 , I912. 
tion and application to the construction of many ingenious pieces of apparatus have been frequently described by him in his lectures throughout the country. Primarily designed for introducing large electrodes into glass vacuum tubes, its usefulness in the laboratory was readily apparent. The procedure as worked out has been applied only to joints between soft glass and iron or steel. A flux glass of low melting point is applied to the metal surface, to dissolve the metallic oxide and the metal to some extent, and thus give very intimate contact with the glass. The flux is applied to the inner side of the metal tube and the seal is then made to the flux glass.

For some years E. O. Sperling, glassblower at this Bureau, has successfully made soft glass to steel joints without the use of a flux glass. In this case it is necessary to heat the steel much hotter. The soft glass acts as its own flux, though it dissolves the iron oxide to a much smaller extent than is the case in the Kraus joint.

\section{Construction of the Joints.}

A. Soldered Joints.-The following procedure in making these joints has been used with gratifying results. Although, as will be shown later, it is possible that certain steps may be omitted without interfering seriously with the strength of the joint, the procedure as given has been found to give certain and reliable restlts. It has been applied only to the joining of glass and metal tubing. The glass tube is so chosen as to fit snugly for from 15 to $20 \mathrm{~mm}$. of its length into the metal tube. It is convenient to have the end of the glass tube fit against a shoulder in the metal tube as shown in Fig. Ia. The inside of the metal tube is tinned up to the shoulder with commercially pure tin, leaving a slight excess of tin on the surface, particularly if the tubes do not fit very closely. In place of tin, common solder or pure lead has been used successfully. The glass tube after roughening slightly with sand or emery paper is platinized over a length of $20 \mathrm{~mm}$. or more by applying a colloidal solution of platinum ${ }^{1}$ in

' Several methods for preparing this solution, which has been extensively used for the preparation of platinum mirrors, have been proposed. Practically every method is some variation of the original solutions patented in England by Basserot in 1859 ("Repertory of Patent-Inventions, June," I859, p. 485; Dingl. Poly. J., I53, 42) and in France by Dodé in 1865 (described by Salvétat. Bull. Soc. Encouragement, Sept., 1865, p. 526; Dingl. Poly. $J$., 177, 79). Solutions prepared as follows have been found very satisfactory. $x$. Ten per cent. platinic chloride solution, equivalent to one $g$. of platinic chloride, is evaporated to dryness in a porcelain evaporating dish, and dissolved in a minimum quantity of absolute alcohol. This solution is added very slowly with stirring to $6 \mathrm{cc}$. of lavender oil in a container cocled in ice. Burgundy pitch is added to the warmed solution until the latter has the desired consistency. 2. One part of pure neutral platinic chloride prepared by evaporating the $10 \%$ solution to dryness is moistened with a few drops of absolute alcohol and ground finely in an iced mortar with ro parts of lavender oil, adding the latter gradually in small quantities. 3. (Ascribed to Kundt by Kohlratisch, "Lehrbuch der prakt. Physik," rate Auflage, rgr 4.s 
lavender oil mixed with Burgundy pitch. One or two drops of this mixture are applied to the slightly warmed surface and flowed into a film, which is then heated carefully to drive off the volatile material, and finally beated to an incipient red heat to burn off the carbonaceous material and fuse the platinum into the glass.

One application of any of the platinum solutions made up as described, is generally sufficient. If the coating seems too thin, the operation may be repeated. Using a slightly acid solution of zinc chloride as soldering flux, the two parts are heated gradually over a Bunsen flame until the tin is well melted. The glass part is inserted into the metal tube and the whole is allowed to cool slowly and uniformly. The platinum surface should not be tinned before making the joint as the platinum is likely to be removed in this operation. Much less care is required in platinizing and in making the joint if Pyrex glass tubing is used.

Joints have been made by this method with glass tubing up to $40 \mathrm{~mm}$. external diameter, but the smaller sizes are much more easily made. Wall thicknesses of metal tubing from 0.5 to $2 \mathrm{~mm}$. have been successfully used, but the lesser thicknesses give more certain results. Iron, steel, copper, brass and nickel have been successfully used, the only requirement being that the metal part must be wetted by tir.

B. Fused Joints.-Glass-platinum joints have been made with platinum tubing of either 0.1 or $0.15 \mathrm{~mm}$. wall thickness. The glass should preferably have the same coefficient of expansion as the platinum. The best joints so far made were of Jena $397^{\text {III }}$ glass, ${ }^{1}$ although one fairly good joint was made with Pyrex. The platinum forms the inner member of the joint and the length of the seal is usually from 5 to ro $\mathrm{mm}$. The construction of the joint requires skill in glass blowing but no special manipulation. There are numerous references in the literature to joints of this kind.

The fiux for the Kraus joint is made by melting in a crucible equal parts by weight of zinc oxide, borax and powdered soda glass. The flux may be drawn or cast into rods for convenience in use. Its composition and use are covered by patent.

A method of making such joints which is particularly applicable to large tubes is described in U. S. Patent No. $\mathrm{r}, 046,084$ by C. A. Kraus. Joints of the smaller sizes are comparatively much easier to make and p. 37). One g. of platinic chloride is dissolved in $3.5 \mathrm{cc}$. of absolute alcohol. Ten cc. of a concentrated alcoholic solution of boric acid is added and the whole is treated with $25 \mathrm{cc}$. of a mixture of lavender oil and Venetian turpentine in proportions to give the desired consistency. For giving a coating suitable for joints of the chatacter described in this paper, the consistency of the platinizing solution is of little importance. Platinizing solutions which have been kept for several years gradually thicken when exposed to the air but deposit no platinum, and can still be used with satisfactory results.

1 The Corning Glass Works also make a special glass for sealing to platinum, 
considerable variations in construction are permissible. The metal shell has been made in a number of different shapes, some of which are shown in Fig. I. Kraus uses a spun shell of steel (Fig. Id). The spun shell is lined with a thin layer of flux and then with soda glass by blowing the glass into the shell. The glass tube to be sealed in is flared out to a flat ring of a width equal to from one to three times the thickness of the
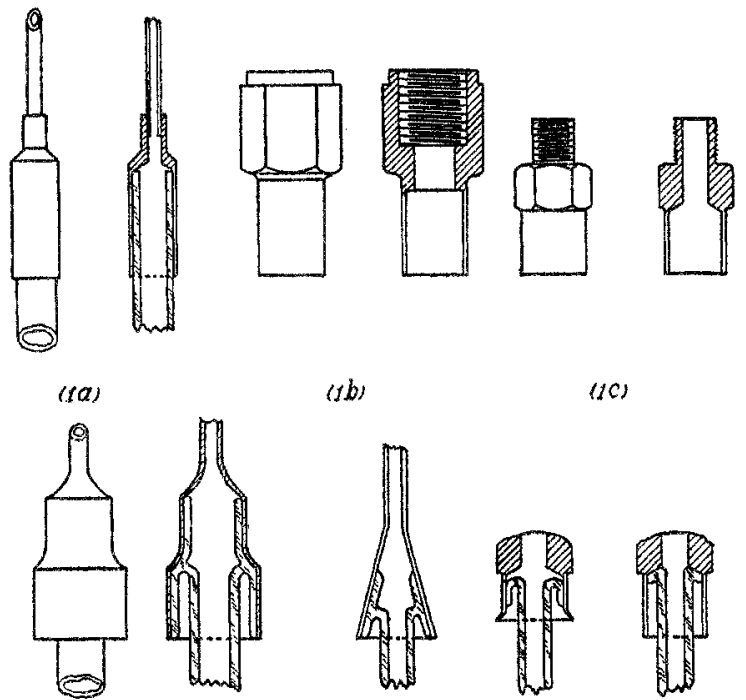

$(1 b)$

$(10)$

(1d)

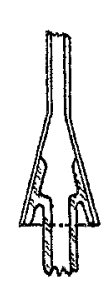

(1e)

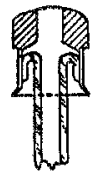

(1f)

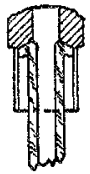

(lg)

Fro.1 Various types of giass-metal joints and saps.

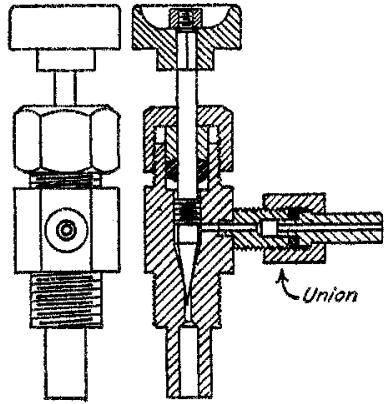

FIc. 2a. Needle value Scale - Full size

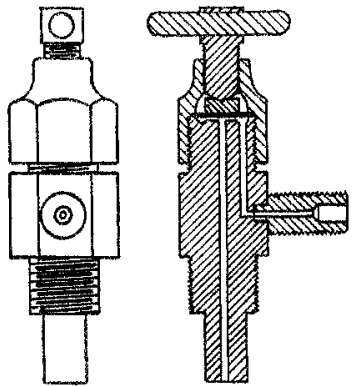

E1a. 210 Diaphragm valve scale-Full size

wall of the tube. The plane of this ring is normal to the axis of the tube. The tube and shell are heated and the tube introduced into the shell so that the edge of the ring presses against the shoulder in the shell. Fusion is completed by heating the outside of the shell, in such a way as to keep the glass tube cool enough to avoid deformation.

The construction described has been simplified in various ways. The 
necessity of using a shouldered shell may be avoided by the use of a conical shell (Fig. re). Cylindrical shells flared at the end have also been used. In these the lining of soda glass may be omitted, its function being performed by the outer part of the flared ring on the glass tube which is deformed on insertion, as shown in Fig. If. A simple cylindrical shell with the glass pressed against the bottom of the shell as shown in Fig. I $g$ has also been successfully used. In all cases, the flared ring should meet the outer member at nearly a right angle. It is not essential that the metal shell be thin.

Attempts at this Bureau to make joints between metal and Pyrex glass or porcelain have so far been unsuccessful.

\section{Auxiliary Metal Parts.}

The metal caps used in making the joints are made of such form that connection to other apparatus can be conveniently made. The simplest form of cap is one into which a metal tube is brazed or soldered. More generally useftul forms are those which have a threaded connection which forms one member of a union. Several of the types of caps which have been used are shown in Fig. I. In quantitative work with compressed and liquefied gases the ordinary stopcocks are not applicable, and valves must be used instead. The 2 types, a needle and a diaphragm valve, which have been most used, are shown in Fig. 2. An important feature of these valves is their small size and light weight. The needle valves are preferred except where the presence of the packing may prove objectionable; since, on account of the manner of seating, the diaphragm is not as easily closed and the closure is likely to be affected by small irregularities on the seating surfaces.

The valves are screwed into the metal caps, with a tin washer to make the joint tight. Metal to metal joints, which, if the proper care is used, may be made and broken without changing the weight of either part, are satisfactorily made by the union shown in Fig. $2 a$, which has a tin washer between the 2 metal surfaces. A fiber washer may be substituted for the tin in cases where contamination of the material will not result.

\section{Tests of Joints.}

Joints of this type have been used for several years for a variety of purposes which required them to be vacuum tight and to hold pressures up to 50 or 60 atmospheres. In addition, a few tests in which they were submitted to extreme conditions have been carried out. The pressure was attained by means of a hydraulic gage tester and the pressures could be read to about 5 atmospheres and held stationary for a short time. The limit of the apparatus was 400 atmospheres, a pressure well above the safety point for glass tubing in general.

Soldered Joint.-The internal pressure at which a joint of this type 
disrupts will depend upon the form and material of the metal cap, the manner of soldering, and the thickness and uniformity of wall of the glass tubing. Most of the tests were carried out on joints of the dimensions found most useful in our laboratory work, that is a steel or brass cap (Figs. I $b$ and $c$ ) with wall thickness of $0.5 \mathrm{~mm}$. and glass tubing of $8.5 \mathrm{~mm}$. external diameter and from 6 to $7 \mathrm{~mm}$. internal diameter. In addition tests were carried out to obtain some information on the effect of each of the main factors involved. A considerable number of joints of this size, made as described in the section on construction of joints, which were first tested and found vacuum tight, were disrupted at pressures ranging from Ioo to 220 atmospheres, the glass tubing shattering in every case. When a brass cap and capillary glass tubing of I mm. bore were used, the tubing was forced out at 250 atmospheres. When a steel cap was used, joints with such capillary tubing still held at 400 atmospheres. Two joints made with glass tubing I $x$ mm. outside diameter and about I mm. thick (but rather non-uniform) and with brass caps, held to 140 and 160 atmospheres, respectively. One joint with a steel cap $2 \mathrm{~mm}$. thick, was much more difficult to make tight, but held to 320 atmospheres, when the glass shattered. Joints made with tubes up to $40 \mathrm{~mm}$. in diameter have been found to be vacuum tight. Joints made with steel or brass caps were repeatedly immersed in oil at $200^{\circ}$, and cooled in air after each in. mersion without any noticeable effect upon their ability to hold a vacuum or internal pressure. When 4 joints thus treated were subsequently tested, the glass tubing shattered at from 130 to 200 atmospheres. Joints exposed to liquid air temperatures were vacum tight at that temperature and remained so on warming up to room temperature.

No specific tests were made to determine the resistance of the joints to mechanical shock. However, experience in the use of this joint has shown no case of breaking except where the glass tubing itself might well be expected to break.

Certain modifications in making this type of joint were tested. In order to obtain good results it does not seem necessary to roughen the glass before platinizing. Joints can also be made without platinizing the glass. Six joints were made in this way, using brass caps in all cases and capillary glass tubing. In 3 cases where the glass was roughened, the tubes blew out at 80, Ioo and 150 atmospheres; in 3 cases where the glass was not roughened, the tubes blew out at I60, I70 and 230 atmospheres. It seems probable that roughening the glass without subsequent platinizing merely interrupts the continuity of contact between the tin and glass, thus decreasing the strength. The tin appears to wet the glass and the strength of the unplatinized joint is probably due to that phenomenon rather than to the soft metal acting as a washer between the brass or steel and the glass. Inspection of the platinized joints after sepa- 
ration of the glass and metal shows that the tin flows on and clings to the platinized glass as if the latter were entirely of metal. More reliable and apparently stronger joints are, however, more easily obtained with the platinized glass, since in only one case with such glass was it possible to blow out the tube before the glass shattered. Soft solder $(1 / 2$ lead and $1 / 2$ tin) may be substituted for tin, but the joint will be more difficult to make and the result will be less certain.

Four joints were made using pure lead as the solder between the thinwalled platinized glass and the steel cap. When tested the glass tubing shattered at from I 75 to 275 atmospheres. A similar joint using capillary glass tubing held up to 400 atmospheres when the glass tubing shattered. A lead joint will remain vacuum tight up to $250^{\circ}$. Six joints were made according to Cailletet's directions; that is, platinizing the glass, copper plating the platinum, and then soldering the copper plated glass to the metal with tin. When tested they failed between 200 and 300 atmospheres pressure, the glass tubing being disrupted in every case. The joints were made by nickel-plating the platinized glass and then soldering the nickel-plated glass to the metal, using tin as solder. These joints held to almost 300 atmospheres when the glass finally disrupted.

Fused Joints. - Failure in the construction of joints of the Kraus type is at once evidenced by cracks or by the glass tube shattering at comparatively low pressures. To allow for the proper disposition of the seal in joints of this type in a steel tube $9 \mathrm{~mm}$. internal diameter, the external diameter of the glass tube must be not more than $7 \mathrm{~mm}$. , thus making the internal diameter of the tube considerably smaller than in the case of the soldered joint. Joints of this character hold from yo up to, in a few cases, 360 atmospheres. It appears, however, that the tube fails first at the joint. In one case a crack was heard at 20 atmospheres, but the joint held to 60 atmospheres. The experience at this Burear with this type of joint indicates that it is somewhat more difficult to make, and is considerably more fragile than the soldered joint. It has rendered best service where it can be clamped into position, or where it is to be used with mercury, since mercury attacks the solder in a soldered joint. Joints made without flux glass have been successfully used in such cases, and have held pressures of many atmospheres. Joints of this type are put together at a temperature very much higher than that at which they are to be used. In spite of the great strains undoubtedly existing in the glass tubes near the joint, they have given surprisingly. good results both in handling and in their resistance to internal pressure.

No test of the glass-platinum joints under pressure were made. Joints of this type were not injured by repeated immersion in the vapor of boiling sulfur $\left(445^{\circ}\right)$ or in liquid air $\left(-190^{\circ}\right)$. 


\section{Applications.}

A.--The soldered joint was devised for and has been used mostly in connecting glass bulb containers to metal valves, thus permitting the introduction, observation, withdrawal and accurate weighing of comparatively large quantities of liquefied gases under pressure. It has been very useful in conducting the analysis and testing of liquid anhydrous ammonia ${ }^{1}$ in which bulbs up to I25 cc. capacity have been employed. A metal to glass joint made with hard de Khotinsky cement will hold liquid ammonia for at most only a few hours. Keyes ${ }^{2}$ has employed a shellac and oil of tar composition for this purpose, but says nothing as to the length of time it resists the action of ammonia. Round-bottom flasks of $500 \mathrm{cc}$. capacity with necks drawn down to $9 \mathrm{~mm}$. outside diameter have served in the handling of ethyl chloride (Fig. $3^{a}$ ). Small bulbs up to ro cc. have been used in handling liquid carbon dioxide (Fig. $3^{b}$ ).

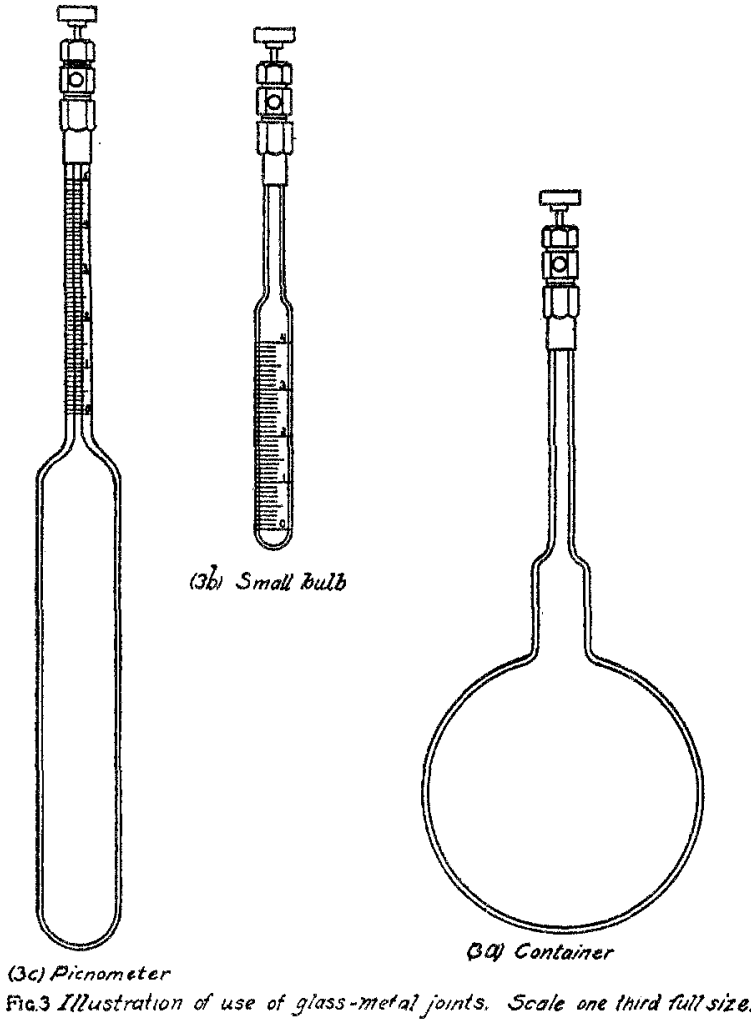

B.-Inasmuch as it was found that the containers mentioned above could be weighed reproducibly to 0 . I $\mathrm{mg}$. and with proper care in handling

${ }_{1}^{1}$ E. C. McKelvy and C. S. Taylor, Am. Soc. Refrig. Eng., 3, 36 (r9r7).

${ }^{2}$ Keyes, This JotmRai, 40, 28 ( (91 8 ). 
and the proper type of valve, remained constant in weight for long periods, similar apparatus was constructed with a graduated capillary to serve as a picnometer in determining the density of liquefied gases and volatile liquids (Fig: 3c). With due precautions and the necessary corrections, picnometers of this kind have given results on the density of liquid ethyl chloride at $25^{\circ}$, which are reproducible with precision and are in excellent agreement with determinations carried out in sealed glass dilatometers. A few determinations of the density of liquid ammonia and of liquid methyl chloride have also been made with this container.

C.- - This type of container has been applied to the determination of the density of ammonia under normal conditions of temperature and pressure by using it as a small easily weighed container into which the gas can be condensed from the calibrated bulb of large volume in which the temperature and pressure of the gas are measured. A somewhat similar method was first used by Prof. E. W. Morley ${ }^{1}$ in determining the density of hydrogen, and by Maass and Russell. ${ }^{2}$ It was found that the tube containing the liquefied gas under its own vapor pressure, and the empty container, could be weighed with great reproducibility when the necessary care and precautions in making and breaking joints were observed. The advantages of such a method are readily apparent.

D.-T'The Kratis joint could doubtless be used for the above mentioned applications, but it has been mainly applied to uses not involving the weighing of the part.

Both types of joints have been applied to the following uses. First, to connect apparatus such as steel cylinder used for fractional distillations at high pressures, to glass apparatus in which distillations at pressures below atmospheric are conducted. In this way contamination in transfer may be avoided. Second, in making up by a direct weighing procedure binary mixtures of known concentration of liquefied gases or volatile liquids.

The Kraus joint has been successfully applied in the construction of a multiple U-tube mercury pressure gage ${ }^{3}$ for the reading of pressure differences up to 15 atmospheres, where it was necessary for mercury to pass through the joint. Such joints are regularly tested to 140 atmospheres pressure. Similar joints of a variety of sizes have been used with success in the construction of apparatus for use in the calorimetry of gases where the joints are required to be vacuum tight and resistant to internal pressure over a considerable range of temperature.

The joints made without flux glass have been applied successfully to apparatus for measuring by the static method vapor pressures up to 30

${ }^{1}$ Morley, Smithsonian Inst. Pub. Contributions to Knowledge, 980, 64-72 (1895).

"Maass and Russell, This Journal, 40, 1847-52 (I9I8).

a Dickinson and Meyers, Bur. Standards Bull. (to be published shortly). 
atmospheres, under conditions where the possible passage of mercury must be provided for. These joints were tested to 50 atmospheres before use.

Acknowledgments are due to H. F. Stimson and C. H. Meyers, of this Bureau, for assistance and suggestions.

\section{Summary.}

r. Methods for the construction of 2 types of metal to glass joints have been given together with the results of tests upon their behavior on handling, their vacuum tightness and their resistance to internal pressure.

2. A reproducible and quantitative method for making and breaking connections between metal and glass or glass and glass is given.

3. Several types of apparatus and laboratory work in which these joints can be successfully used have been outlined.

WAshixgTON, D. C.

[CONtributron from the Wolcot' GibBs Meimordat, laboratory of Harvard UNIVERSITY.]

\section{A CALORIMETRIC METHOD FOR STANDARDIZING THERMO- METERS BY ELECTRICAL ENERGY.}

BY THEODORE W. Richards aNd SHTSURo TaMaru.

Received April 23, 1920.

In 1915 Dr. Thorbergur Thorvaldson, in collaboration with one of the present authors, showed that it was possible to calibrate an interval in the thermometric scale near the temperature of the room with considerable accuracy by means of a definite chemical reaction repeated step by step at intervals over the scale. This method (which demands only very simple apparatus) might serve, when properly carried out, a useful purpose for those whose experimental appliances are limited. Nevertheless, the change in heat capacity, and of heat of reaction with the temperature, cause complications in the calculation; and these data demand more thorough study as to their details before the method can attain the highest accuracy of which it is capable.

Another somewhat similar method is the subject of the present paper. In this method, the source of energy is not a chemical reaction, but rather electrical energy supplied at known voltage through a definite constant resistance. The method consists simply in thus supplying heat in successive small equal quantities to a calorimeter, noting the reading of the thermometers produced by each step. From the known heat capacity of the system, the rise of temperature which ought to occur is easily calculated. The comparison of the actual rise in each case with that calctlated should give the error of the thermometer over each interval concerned. The accuracy clearly depends first, upon the accuracy of meas-

1 Richards and Thorvaldson, THis JovrNat, 37, 8r (rg15). 